\title{
Enhancing Agriculture Based Livelihoods through Technology Innovation: Deploying M-Community for Farmers in Malaysia
}

\author{
Lee Heng Wei, Mohd Azam Osman, Abdullah Zawawi Talib, Wong Poh Lee \\ School of Computer Sciences \\ Universiti Sains Malaysia \\ Penang, Malaysia
}

\begin{abstract}
The inability of getting instant access to information which is crucial to farming has posed the farmers to greater vulnerability of their livelihoods. Currently, farmers are not exposed to ICT integrated application which can help them to manage their daily farming activities and provide accurate weather forecast. Therefore, GreenEve2Peace that uses a modern way of information dissemination by utilizing mobile technology is introduced for the farming community. This approach is designed to provide timely information on paddy planting activities, pest and disease control, weather forecast service and allow two way communications among the farmers and the authorities via the Short Message Service (SMS) and online portal. In this paper, we relate our experience in deploying the approach for farming community in a selected area in Malaysia. The approach manage to improve farmers' livelihood by providing them better access to information, enhance their human capital, strengthen the connectivity among farmers and the authority, and saves cost and time. The problems in this study included farmers acceptance level towards ICT integration in agriculture and to identify a sustainable business model to deliver the service without relying on governmental support.
\end{abstract}

\section{Introduction}

1. Increasing international oil price, adverse weather conditions, strong demands from the Asia, and European financial crisis have led to the recent surge in global food prices [1]. Global food prices have increased $8 \%$ since December 2011, and were only $6 \%$ below their historical peak. An increase in global food price dramatically increases the poverty level especially in developing countries. Therefore, it is important to identify ways to improve agriculture output and enhance agriculture based livelihoods. Past research suggested that it is at least twice as effective in reducing poverty through, inter alia, growth in agriculture [2]. As a result, technology innovation is indeed the stimulus to the agriculture growth where small-holder farmers are made more competitive and sustainable. The International Fund for Agricultural Development (IFAD) has shown that one of the causes that lead to poverty is the limited access to information and poor communication technology [3]. Poor people need information in order to improve their livelihoods but most of the times they have limited access to information. In this context, the argument is that limited access to information will subsequently increase their information searching cost in farming activities and subsequently deteriorating their income level. Pertaining to this argument, this paper considers the specific role of information and communications technology (ICT) in reducing information searching cost by enabling effective and affordable communication channel in farming community.

\section{The Agriculture Value Chain}

Based on the input from a focus group discussion with a group of farmers, the agriculture value chain was identified to be comprised of five stages. The agriculture value chain is shown in Figure 1.

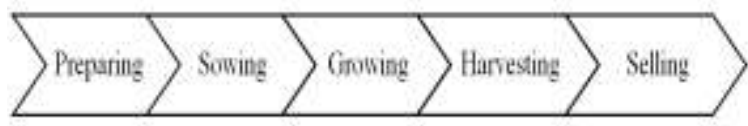

Figure 1. The Agriculture Value Chain

According to this value chain, farmers need to incur a significant amount of transaction cost in each of the stage in the value chain in order to remain competitive in the market. There are several components of the total transaction cost which include information cost, negotiation cost, monitoring cost, coordination cost, and enforcement cost [4].

In the first stage of the value chain, "Preparing", farmers need to prepare the working capital financing, land preparation machinery, and also preparing the schedule for the subsequent stages in the value chain that need to be carried out. They need information on the availability of financial aids and labor power to help them to go through the rest of the stage. The transaction cost incurred in this stage includes information searching for loans or 
incentives from the government. Farmers need to pay frequent visit to the local bank to apply for loan and also finding guarantor. Meanwhile, they also need to visit the local government agriculture agency to register and provide information for the subsidized fertilizer and pesticide. Other than that, they also need to search for suitable manpower from the labor market. In addition, the transaction cost might include frequent visit to farmer's association and other farmer to collect advice on which type of crops to plants

Subsequently, in the "Sowing" stage, the farmers need to decide whether to purchase seeds for the crops or use their own seeds based on the crop they planted earlier. They are required to search for better seeds from the seeds market in order to guarantee better yield. Most of the time, this activity is done through travelling from one place to another place to get better seeds. As a result, high transportation cost is involved.

Next, in the "Growing" stage, application of water, fertilizer and pesticides take place. In this stage, farmers need to look for suitable fertilizer and pesticides for their crops. In addition, they also need information regarding the weather condition in order to ensure that the application of fertilizer and pesticides will not be washed away by heavy rain. The information searching cost incurred through telephone calls to related agency results in high transaction cost. For certain farmers who are eligible for subsidized fertilizer and pesticides, they need to stay alert on the information related to the collection of the subsidized fertilizer and pesticides from the government agency. Unfortunately, for most of the time due to the inefficiency of the communication method used by the government agency, some of the farmers miss the collection date, resulting them having to buy the fertilizer and pesticides at the market price. Therefore, they might incur even higher transaction cost like making telephone calls to check for the availability of the fertilizer and pesticides or going the fertilizer and pesticides distributor for the same information.

In the fourth stage, "Harvesting", farmers need to find labors for harvesting and locate appropriate store for storing. They also require weather forecast information for the best timing to harvest.

In the final stage, "Selling", farmers need the information of the market prices of their crops from various markets and also search for transportation method to transport their crop to the particular market. Most of the time, high transaction is incured in this stage since farmers are required to visit the market physically to collect the information on the market prices. Sometimes, due to the lack of market information access, farmers need to scale down their selling price as their crops are not in demand.

Therefore, any interventions targeted to help the farmers should aim at reducing the transaction cost through the stage. Reducing the transaction cost would directly enable the small-holder farmers to be more competitive and enhance their livelihoods through better income. Consequently, the specific role played by ICT should be considered based on its ability to reduce the transaction cost by providing an effective means for communication and information searching.

\section{Mobile Applications for Agriculture Development}

Most of the information related to agriculture are available at the national agriculture agency. In spite of that farmers are unable to access the information because the required tools to access the information are not available to them or too expensive to acquire. Farmers rarely have access to a specialized portal for the breadth of information required by them over the agriculture value chain.

Recently, there has been a rapid increase in mobile phone usage in the developing countries. Mobile technology offers an effective means of connecting people especially in the developing countries due to the special features of mobile technologies like low cost handsets and penetration of mobile phone networks globally. Tens of millions of people that never had regular access to a fixed-line telephone or computer now use mobile devices as daily communication and data transfer tools [5]. Figure 2 shows that people in the developing countries have extensive access to mobile technology even though other ICT technologies are relatively scarce.

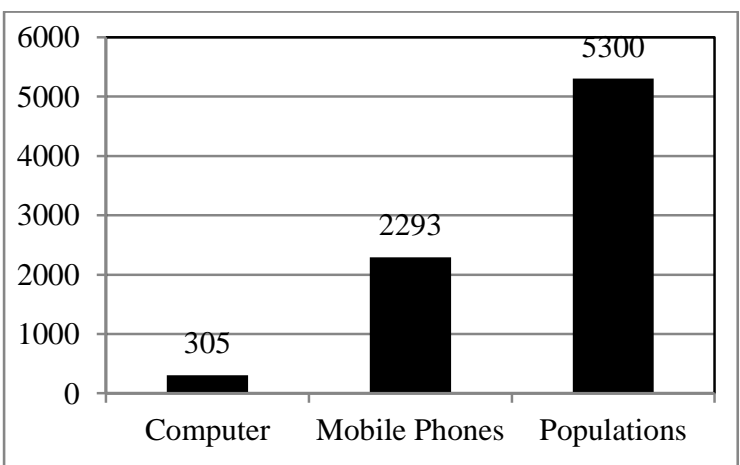

Figure 2. Number of ICT users compared to total population in Developing Countries 2009 (millions)

[5]

As a result of the high penetration of mobile phones worldwide, a variety of mobile application platforms for agriculture have come onto the market to address different issues in the agriculture value chain. The platforms possess different functions and interface, and one of the way in which they can be differentiated is by their intended purpose. Basically, the platforms that existed today can be categorized 
into three main purposes, which are "General Purpose", "Agriculture Adaption Purpose", and "Agriculture Specific Purpose".

The "General Purpose" platforms provide general functionality to serve the broad needs. It usually contains inbound and outbound Short Messaging Service (SMS) to allow people to communicate regarding agriculture issues like information sharing, performing survey, and expanding the contact groups. Example of such platforms includes Frontline SMS (used in Cambodia for crops price information service). However, this platform has less pre-built function for specific agriculture needs like market price checking from multiple locations.

The "Agriculture Adaption Purpose" platforms are horizontal market platforms which they can be used in many different industries. They adapt the functionalities of the platform used in other sectors and modify them to the agriculture context. The platforms adapt the SMS function by allowing the user to use SMS messaging to receive information on local agriculture related news, market demand and supply information, weather forecasts, latest crop price and other information from the local agriculture agency. Besides, they also adapt a marketplace function for farmers to sell their crops online and allow buyers to view the crops and check the price information. Examples of such platform include Souktel - Farm Price SMS service, and Voxiva's eSoko.

Finally, the "Agriculture Specific Purpose" platforms were specially developed to cater the needs of agriculture sector and therefore they are considered as vertical marker platform. The functionalities of this type of platform are usually hard to be adapted in other sector. The platform usually provides mobile-based agriculture market information exchange for individuals and businesses. It also provides networking service for farmers to develop an agriculture community. Meanwhile, it also serves voice-based information service via call center.

\section{Mobile Agriculture Projects in Developing Nations}

\subsection{Sri Lanka}

Poverty among farmers in Sri Lanka accounted for $82 \%$ of the poor in the country. This is due to the fact that farmers are unable to plan the type, volume and timing of crop harvest and cultivations to reflect demand condition due to the high seasonal, inter- and intra-day price volatilities. A non-profit company called Govi Gnana Seva (GSS) or 'Farmer Intelligence Service' has worked in partnership with the country largest mobile operator, Dialog Axiata PLC to develop a mobile agriculture-based network called Dialog's Tradenet. The Dialog Tradenet Platform allows agriculture price information collected by GSS to be made available on mobile phones and accessed through SMS, Internet, WAP, and dedicated call center. The service provided by Dialog Tradenet include price alerts and market exchange (user can post buy and sell orders). The platform is aimed to provide real-time access to market price information to the farmers in order to help them improve their decision making on when to harvest and sell their crops.

\subsection{India}

Most of the farmers in India are small and marginal and do not have access to crucial agriculture information that could affect their crops growth and productivity. In order to overcome the problem, an ICT system called OneFarm has been developed. The server in the system will send automated SMS to all registered farmers. These SMS alerts contain information regarding the age and date of sowing crop, crop management practices, pest and diseases management, and also guidance on maintaining the soil fertility. The user can send reports and do self-updating of all the operations they have carried out with the system. The system can send advices based on their report via interactive voice response system and SMS in the local language.

\section{Case Study in Malaysia: The Setting}

The world population has reached 7 billion on 31 October 2011. In the Malaysian context, the country's population has been growing from 23.3 million in 2000 to 28.3 million in 2010, a total of 21.5 percent increase in population in 10 years [6]. Therefore, Malaysia is expected to increase their paddy cultivation and rice production to feed the growing population. The Malaysian government has addressed the need in the Third National Agricultural Policy (1998-2010) where eight granary areas were designated as permanent paddy producing areas in order to realize a minimum of 65 percent selfsufficiency level (SSL) for rice [7]. The effort to increase SSL for rice is further emphasized in the Eight Malaysia Plan (2001-2005) and Ninth Malaysia Plan (2006-2010) where SSL is targeted to achieve 72 percent in 2005 and 90 percent in 2010 respectively [8]. In 2010, the demand for rice in the country was recorded at 2300 tonne while the production of rice in the country was recorded at 1642 tonne which is equivalent to 71.4 percent of SSL, 18.6 percent below the targeted SSL in the Ninth Malaysia plan [9]. The Ministry's report even mentioned that this makes Malaysia to be the net rice importer and the quantity of rice imported is 
increasing year by year. In addition, a study has shown that Malaysia is an inefficient producer of rice as the price of locally produced rice is double compared to the price of the imported rice [10].

The rural population and traditional farmers are mostly involved in the cultivation of rice in Malaysia. The labor forces in this subsector are usually aged and receive low-level of education. Subsequently, poverty and dependency are highly associated with them. As rice is the staple food in the country, the cultivation of rice has always been accorded with special emphasis from the government which results in a fiscal drain on the nation. Most of the farmers rely on income support from the government [10]. Therefore, this phenomenon has proven that paddy subsector in Malaysia is nonviable and nonsustainable. Besides, the high cost of material inputs (labor, farm power, fertilizer, and agro-chemicals) has resulted in declined profit margins. Consequently, investment in paddy cultivation is unappealing and the situation worsens with the open-market competition of paddy. Solutions to this issue have been given to increase the productivity of paddy cultivation through the adoption of new farming technology and strengthening on the research capacity. As mentioned earlier, one of the reasons of poverty among the farmers are due to the constraints they faced in accessing information and poor communication technology. Poor people need information to improve their livelihoods but most of the times they are not easily available. The communications and knowledge sharing capabilities of ICT will enhance the livelihoods of the poor farmers. ICT is able to provide extended agriculture services like timely market price information, connecting farming community to overcome the impact of globalization, and understanding crop diseases and soil nutrition issues.

\section{Mobile Penetration in Malaysia}

In the Malaysian context, $92.6 \%$ of household in Malaysia possessed at least a mobile phone in 2009 (Table 1) [11]. The report also shows that by 2009 , there were 100.8 mobile phones per 100 Malaysians compared to 2000 , where there were only $21.8 \%$. Meanwhile, Malaysian mobile phone user recorded 756 SMS per subscriptions throughout 2008, equivalent to approximately 2 SMS per day (Table 2 ) [12]. Although, these statistics might not apply in agriculture sector, mobile phone is increasingly important to Malaysian agro-based entrepreneurs and producers as an infrastructure service for improving the efficiency of agriculture industry [13]. A study has suggested that the high adoption of mobile phone opens up opportunities for marketer to provide agriculture information through SMS [14]. The study also shows that people in the developing countries have plentiful access to mobile technology even though other ICT technologies are relatively scarce [14].

Table 1. Household possession of mobile phones: 2006-2009 [12]

\begin{tabular}{|l|c|c|c|c|}
\hline As Stated & $\mathbf{2 0 0 5}$ & $\mathbf{2 0 0 6}$ & $\mathbf{2 0 0 7}$ & $\mathbf{2 0 0 8}$ \\
\hline $\begin{array}{l}\text { Usage of SMS } \\
\text { service per } \\
\text { Malaysian } \\
\text { mobile phones } \\
\text { subscriptions }\end{array}$ & 1126 & 1713 & 730 & 756 \\
\hline
\end{tabular}

Table 2. Usage of SMS service per Malaysian mobile phones subscriptions [12]

\begin{tabular}{|l|c|c|c|c|}
\hline As Stated & $\mathbf{2 0 0 6}$ & $\mathbf{2 0 0 7}$ & $\mathbf{2 0 0 8}$ & $\mathbf{2 0 0 9}$ \\
\hline $\begin{array}{l}\text { Mobile Phone } \\
\text { \% of } \\
\text { households) }\end{array}$ & 79.1 & 84.6 & 89.4 & 92.6 \\
\hline
\end{tabular}

\section{Deploying GreenEve2Peace - Mobile Community for Farmers in Malaysia}

The School of Computer Sciences of Universiti Sains Malaysia (USM) has initiated a collaboration project with Muda Agricultural Development Authority (MADA) and Suka Setia Section C Farmer's Organization in Simpang Empat Kangkong, Kedah, Malaysia and developed a research program on Mobile Community (MCommunity) for Farming community with the aim of helping them by fostering communication and knowledge sharing capabilities using information and communications technologies (ICT). GreenEve2Peace is intended to enhance the livelihoods of the farmers by filling up the information gaps, raising ICT awareness, building working skills and extending their social networks. It is a web-based application that is designed to advise farmers on paddy planting activities as well as to manage farming activities by providing inexpensive and fast delivery of information to farmers via short message service (SMS). The information includes farming activities such as registration activity and matters regarding information on subsidised fertilizers and seeding period. With this service, it is expected that the paddy farming community will enjoy a better livelihood with more productive and sustainable farming practices.

This project started in 2009, where the School of Computer Sciences, USM with the help of Muda Agricultural Development Authority (MADA) conducted research on the problems faced by the farmers community and developed the prototype system of M-Community GreenEve2Peace. Some of the problems identified include poor harvests resulting from extreme weather, late notifications 
causing crops to be damaged by weeds and pests, and late notifications due to the conventional methods of broadcasting such as using posters and amplifiers. As a result, we have developed a prototype system to solve these problems and presented to MADA in July 2009. In April 2011, we received a Delivering Excellence grant from Universiti Sains Malaysia (USM) to implement the project with the major aim of helping the community.

GreenEve2Peace is a web-based application that deploys SMS based technology to assist the farming community in improving the management of farming activities. It allows inexpensive and fast delivery of information to farmers via SMS. This information includes weather forecasts, paddy disease, schedule of farming activities, and registration periods at the MADA office. GreenEve2Peace cuts down the operational expenses as text messages are much cheaper and timely than postal mails. It also provides a greener approach as it reduces paper wastage and energy consumption. In addition, the application addresses the problems that arise from the conventional means of communication: not all farmers receive the information on time or remember what they have been told. The application is also used to help farmers make better decisions on their farming activities based on weather forecasts. MADA will inform the farmers of the weather forecast generated by the application and offer them advice on sustainable farming practices through SMS. Extreme weather can result in poor harvests, which severely impact the farmers' livelihoods. An example of how this application can benefit farmers is by helping to reduce the risk of seeding the paddy at the wrong time. The same is true when it comes to spraying pesticides, which can also have damaging environmental consequences if administered in unsuitable weather conditions.

\section{System Design}

The system design primarily consists of 3 components namely the users, the interface, and the core system.

Users. The users of GreenEve2Peace are the farmers (registered with MADA), MADA authority and the project administrator. Farmers are the end users of the system where they can obtain and share information via GreenEve2Peace using SMS or through the internet portal. The MADA authority provides the content of the SMS messages and the internet portal. The project administrator plays the role of facilitating the system between the farmers and the MADA authority. The project administrator also helps the farmers in interacting with the system and to solve technical issues faced by the MADA authority.
Interface. GreenEve2Peace helps in disseminating information to farmers in both online and offline manner. In an online environment, the system allows farmers to interact with the system and retrieve required information such as weather forecast, pest attack and news updates through a web browser. The system intelligently collects weather information from various sources and predicts the likelihood of a particular weather condition. In an offline environment where the Internet is scarce, GreenEve2Peace promotes two-way communication where the system is able to broadcast SMS messages as well as to receive messages sent from the farmers. MADA authority can also schedule information to be sent via SMS messages by setting a specified date and time. The interface is aimed to provide a simple and fast delivery medium for farmers and MADA authority to communicate. Examples of the interface are shown in Figure 3 and Figure 4.

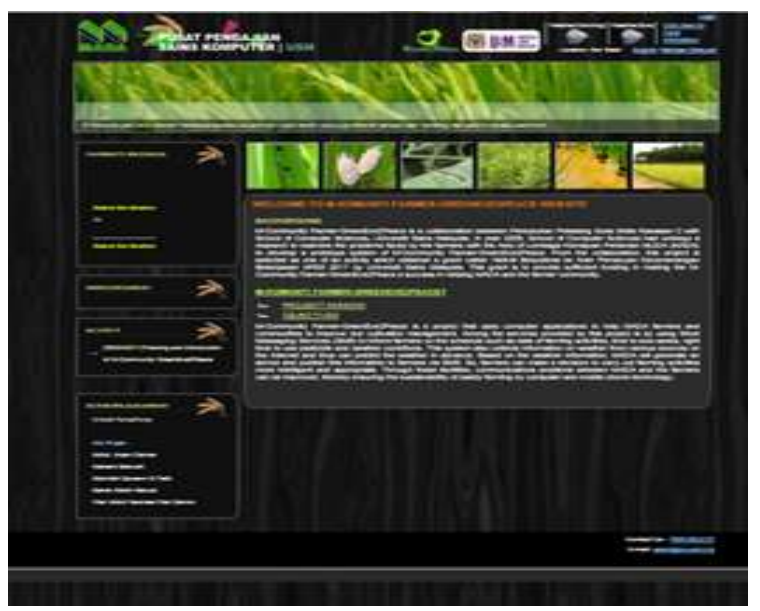

Figure 3. GreenEve2Peace Web Portal

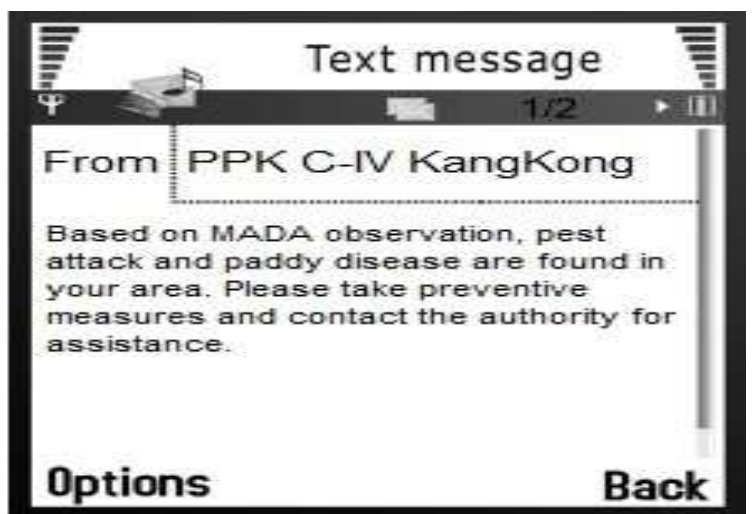

Figure 4. Text Message on pest and disease alert Core System. GreenEve2Peace consists of four modules which are SMS Broadcast Information module, Admin Monitoring module, Data Scheduler module, and Weather Forecast module. The overall system application is shown in Figure 5 


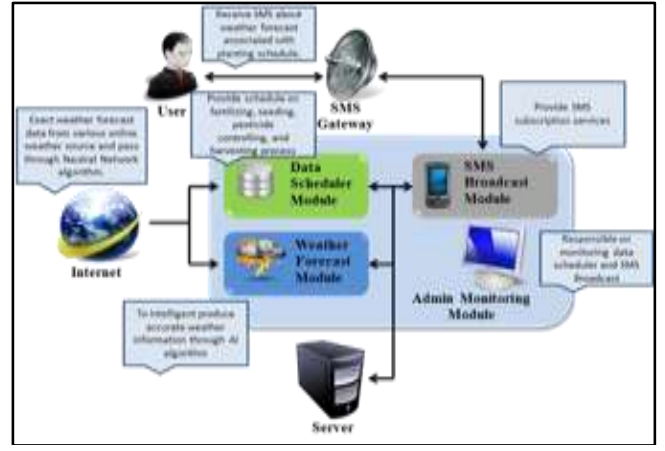

Figure 5. GreenEve2Peace Application [15]

\section{System Deployment}

The prototype of GreenEve2Peace was completed in April 2009 and was introduced to MADA in July 2009. The GreenEve2Peace development milestones are depicted in Table 3.

Table 3. GreenEve2Peace Development Milestones

\begin{tabular}{|c|c|c|}
\hline Milestone & Activities & Objectives \\
\hline $\begin{array}{l}\text { April } \\
2011\end{array}$ & $\begin{array}{l}\text { Gather system } \\
\text { requirements } \\
\text { information and } \\
\text { pre-adoption } \\
\text { system testing }\end{array}$ & $\begin{array}{l}\text { To understand } \\
\text { the user } \\
\text { requirements } \\
\text { and further } \\
\text { enhance the } \\
\text { system. }\end{array}$ \\
\hline May 2011 & $\begin{array}{l}\text { Set up } \\
\text { GreenEve2Peace } \\
\text { platform to the } \\
\text { farming } \\
\text { community and } \\
\text { MADA }\end{array}$ & $\begin{array}{l}\text { To introduce the } \\
\text { system and } \\
\text { provide training } \\
\text { for the users. }\end{array}$ \\
\hline July 2011 & $\begin{array}{l}\text { Deploy } \\
\text { GreenEve2Peace }\end{array}$ & $\begin{array}{l}\text { To help the } \\
\text { MADA officers } \\
\text { to use the } \\
\text { system }\end{array}$ \\
\hline $\begin{array}{l}\text { December } \\
2011\end{array}$ & $\begin{array}{l}\text { Official } \\
\text { launching }\end{array}$ & $\begin{array}{l}\text { To increase the } \\
\text { awareness of } \\
\text { the public and } \\
\text { farming } \\
\text { community } \\
\text { towards the } \\
\text { system }\end{array}$ \\
\hline $\begin{array}{l}\text { January } \\
2012\end{array}$ & $\begin{array}{l}\text { Post-adoption } \\
\text { system evaluation }\end{array}$ & $\begin{array}{l}\text { To gain } \\
\text { feedbacks from } \\
\text { the users } \\
\text { regarding the } \\
\text { system } \\
\text { usefulness and } \\
\text { identify } \\
\text { potential } \\
\text { adoption } \\
\text { barriers. }\end{array}$ \\
\hline
\end{tabular}

This platform was then presented to the farming community as a pilot test in April 2010. The total sample size for application testing stage is around 2000 farmers who come from MADA C-IV area. Due to the lower ICT integration in agriculture in the past, the MADA office and the C-IV area are lacking in ICT infrastructure to set up the GreenEve2Peace platform. Therefore the platform is hosted and installed at the School of Computer Sciences in USM. The involved parties are connected and communicate using Internet and mobile services. With the aim of enhancing the skills of MADA staff and farmers on using ICT, computer skills training was conducted on May 2011(Figure 6). A total of 27 participants (farmers and MADA staff) participated in this two-day training program which was held in USM computer lab.

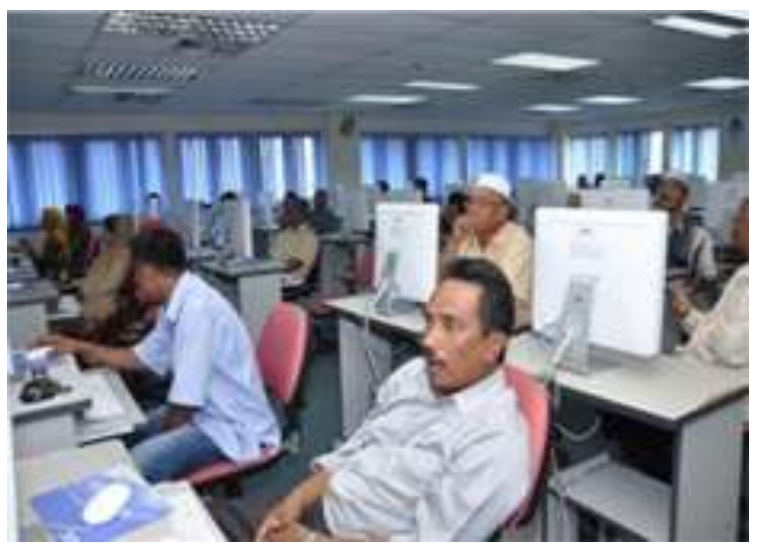

Figure 6. GreenEve2Peace Training Session

The training program manages to give some insight on the acceptance level of farmers and MADA staff towards ICT integration in agriculture. From the MADA staff perspective, they have shown positive attitude towards the system where they claimed that traditional communication method that involves sending letters to the leader of the unit area and then distributing the information by the leaders to the other farmers are slow and troublesome. Sometimes they even need to travel from one area to another and use a mobile loudspeaker to broadcast farming scheduling information to the farmers. On the other hand, GreenEve2Peace allows them to send information to all farmers by just doing some simple clicking. Consequently, GreenEve2Peace encourages more timely and cost-effective means of information dissemination. From the farmers' perspectives, GreenEve2Peace allows them to receive and keep a copy of the important information sent by MADA. They can retrieve the message at any time they want to recall the information. Using the conventional methods, the tendency for them to miss out important information is high as they have no way to retrieve the information again. This is attested by MADA officers. Some farmers tend to miss out the date for 
them to register for their subsidized fertilizers from the authority even though the notice may have been given out a week ago. The farmers and MADA further commend GreenEve2Peace since the system supports greener environment. No paper is needed when the system is utilized. Furthermore, the accurate weather forecasts provided by the system will ensure pesticides sprayed will work efficiently and not be swept into the nearby waterways due to rains which will destroys the ecosystem of the area.

GreenEve2Peace has the capability to store information on the messages sent by the staff. As of 8th August 2012, a total of 6,940 SMS has been sent. As recorded, $9 \%$ of the messages are related to paddy health while $15 \%$ is related to fertilizer registration $(8 \%$ fertilizer registration, $7 \%$ second phase fertilizer application). Mice control contributes $7 \%$ to the total SMS sent. Other messages contribute $69 \%$ which consist of job openings, talks, announcements and speeches. Some sample messages sent are:

- Based on MADA observation, pest attack and paddy disease are detected in your area. Please take immediate action. From PPK-C-IV KangKong (432)

- Project NKEA Paddy Estate Briefing Session. Date 17/7/2011, 9pm, Public Hall Kg Pulai.

- Others: Open Vacancy (Accounting Assistant) STPM, 18-30 years old, closing date: 18/8/2011, Get your forms from PPK-C-IV. (32)

- Fertilizer Registration: Announcement, Closing date for subsidized fertilizer registration on 12/10/2011. (562)

- Water Supply Interruption on 5/11/2011. Please monitor your water reservoir! Speed up the paddy planting activities. MADA-CIV. (564)

- Agriculture Information. First fertilization- mixed 3 begs Serelong - 14 days after sowing. (116)

- Rat Control. Start using the pesticide now. Repeat 3 times weekly for the subsequent 3 weeks after sowing. (483)

\section{The Contributions}

GreenEve2Peace can improve farmers' livelihood in several ways. First of all, it provides an access to information needed by them to improve their productivity. From the timely information they get, farmers can improve their farming practices and increase their output. Besides, GreenEve2Peace also enhances human capital among farmers where they are able to learn new skills especially in the adoption of ICT in traditional agriculture sector. This helps in the transition of the tradition agriculture sector into a high productive and sustainable modern industry. On the other hands, GreenEve2Peace can also supply information to the policy makers and agriculture authorities like MADA and strengthen the bond between them aand the farmers. MADA can better react to the problems faced by the farmers like pest attack and better control of the subsidies given to the farmers. Better communication provided by GreenEve2Peace will result in better saving of cost and time which can be reinvested in other activities that can bring extra benefit to the agriculture industry. The project's scalability will also be expanded to international level. Currently, Memorandum of Agreement (MOA) with Surathani Rajabhat University, Thailand is in progress in order to deploy the system in Thai communities.

\section{Challenges and Lessons Learned}

The main challenge faced in introducing this platform is in the possibility of extending the wide usage of mobile phone to mobile community system [16]. People might show positive response to mobile phone usage but not mobile community system. This might possibly be due to the complicated interfaces, low quality of content, privacy concerns, and low reliability of the system. Besides, it is important to identify a sustainable business model to deliver ICTbased service to rural farmers as most of the ICT inventions are supported by either government or NGOs $[17,18]$. The service provided by the mobile platform should be diversified to include technical information, market information, and news to increase its marketability and thus attract more investment from private sectors.

\section{Conclusion and Future Work}

Implementing GreenEve2Peace has the potential of changing the farming communities' viewpoints on the important of embracing ICT in enhancing their livelihood and opportunities available to them through better access to information. The adoption of better technology is expected to promote the transformation of traditional agriculture to modern agriculture which is expected to increase their level of income and thus eradicating rural poverty. The future work should focus on the ability of personalization where user can customize the information and make the information tailor-made to their needs. In addition, future system should be able to link with other systems like banking, insurance, business intermediaries and government agencies to reduce farmer vulnerability through better information access. Finally, the sustainability issues must also be addressed in order to provide low cost, workable, and user friendly system.

\section{Acknowledgement}

We would like to acknowledge the contribution of School of Computer Sciences, USM, Delivering 
Excellent grant from USM and Muda Agricultural Development Authority (MADA) in supporting this project, all the co-researchers of the grant and also effort from students on the implementation of the system.

\section{References}

[1] Poverty Reduction \& Equity Group. (2012). Food Price Watch. Washington: The World Bank Group.

[2] de Silva, H., \& Ratnadiwakara, D. (2008). Using ICT to Reduce Transaction Cost in Agriculture Through Better Communciation: A Case-Study From Sri Lanka. Colombo: LIRNEasia.

[3] Grimshaw, D. J., \& Kala, S. (2011). Strengthening Rural Livelihoods: The Impacts of Information and Communication Technologies in Asia. Warwickshire: Practical Action Publishing.

[4] Coase, R. H. (1937). The Nature of the Firm. Economica, 4, 386 - 405.

[5] Vital Wave Consulting. (2009). mHealth for Development: The Opportunity of Mobile Technology for Healthcare in the Developing World. Washington DC and Berkshire, UK: UN Foundation and Vodafone Foundation Parthership.

[6] Department of Statistics, Malaysia. (2011, July). Department of Statistics, Malaysia website. Retrieved November 12, 2011, from Population and Housing Census, Malaysia $2010 \quad(2010$ Census $)$ : http://www.statistics.gov.my/portal/download_Populati on/files/census2010/Taburan_Penduduk_dan_Ciriciri_Asas_Demografi.pdf

[7] Ministry of Agriculture and Agro-Based Industry malaysia. (1998). Third National Agricultural Policy (1998 - 2010). Kuala Lumpur: Government Press.

[8] Tey, Y. S., Darham, S., Noh, A. M., \& Idris, N. (2009). Acreage response of Rice: A Case Study in Malaysia. Munich: Munich Personal RePEc Archieve.

[9] Ministry of Agriculture and Agro-Based Industry, Malaysia. (2010). Information Book of Ministry of Agriculture 2010 . Kuala Lumpur: Ministry of Agriculture and Agro-Based Industry, Malaysia.

[10] Man, N., \& Sadiya, I. (2009). Off-Farm Employment Participation Among Paddy Farmers In The Muda Agricultural Development Authority and Kemasin Semerak Granary Areas of Malaysia. Asia-Pacific Development Journal, 16(2), 141-153.

[11] Euromonitor International. (2011, July 6). Passport GMID. Retrieved September 13, 2011, from Consumer Lifestyles in Malaysia: http://ezproxy.usm.my:2387/Portal/Pages/Search/Sea rchResultsList.aspx
[12] Wetpaint.com, inc. (2010, March 21). Digital Media Across Asia. Retrieved July 6, 2011, from Malaysia Mobile Penetration: http://comm215.wetpaint.com/page/Malaysia+Mobil e+Penetration

[13] Shaffril, H. M., Hassan, M. S., Hassan, M. A., \& D'Silva, J. L. (2009). Agro-Based Industry, Mobile Phone and Youth: A Recipe for Success. European Journal of Scientific Research, 36(1), 4148.

[14] Nigel, S., Batchelor, S., Ridley, J., \& Jorgensen , B. (2004). The Impact of Mobile Phone for Africa. Commision of Africa.

[15] Osman, M. A., Talib, A. Z., Sabudin, M., \& Wong, P. L. (2011). GreenEve2Peace: An Advising and Scheduling Management Platform for Farming Community. 10th WSEAS International Conference on Software Engineering, Parallel and Distributed Systems (SEPADS'11) (pp. 90-95). Cambridge: WSEAS.

[16] Wong, P. L., Osman, M. A., Sabudin, M., \& Sulaiman, S. (2010). An Experience on Introducing a Mobile Community Platform: Flying2U. Recent Advances in Software Engineering, Parallel, and Distributed System (pp. 160-165). UK: World Scientific and Engineering Academy and Society.

[17] Rainford, S. (2006). e-Sri Lanka: An Integrated Approach to e-Government Case Study. Sri Lanka: ICT Agency of Sri Lanka.

[18] Kapadia, K. (2005). Developing Information Technology, Informing Technology for Development: A Study of ICT and Rural Development in Sri Lanka. Berkeley: U.C. Berkeley and Sarvodaya Shramadana Movement of Sri Lanka. 